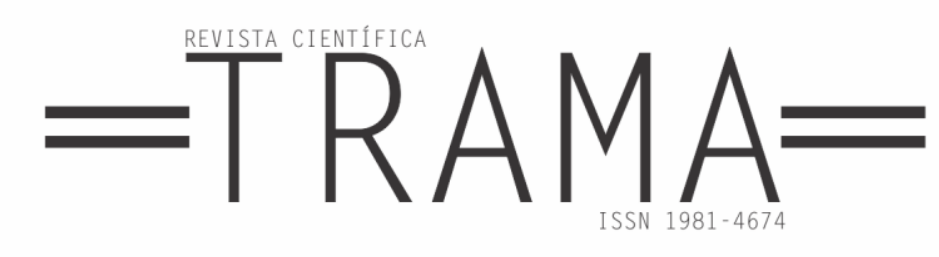

\title{
EdduCaÇão biLÍNGUe MEdiante PRÁticas da LITERATURA SURDA PARA ASCENDÊNCIA E VALORIZAÇÃO CULTURAL E IDENTITÁRIA
}

\author{
Aline Keryn PIN ${ }^{1}$ \\ Joicemara Severo SILVEIRA ${ }^{2}$
}

\begin{abstract}
Resumo: Das inúmeras nuances da educação bilíngue e do contexto Literário, enfatizam-se as pesquisas sobre a Literatura Surda ao longo dos últimos anos. Resultado este da identificação e autoafirmação do povo surdo que busca na divulgação da Literatura Surda a disseminação de suas formas de experimentações visuais. $O$ presente artigo aborda a educação bilíngue mediante práticas desta literatura contribuindo para o processo de valorização da cultura e Identidade Surda mediante representações literárias produzidas por este sujeito. Para tanto, as pesquisas das autoras Karnopp (2008; 2010), Quadros e Sutton-Spence (2006) e Strobel (2009) são indispensáveis na fundamentação teórica deste escrito, pois, retratam o que há de mais avançado no campo teórico das experiências sensoriais da pessoa surda. Assim, a pesquisa desenvolvida busca contribuir para o enriquecimento do conhecimento dos alunos surdos sobre seu povo, sua cultura $e$ construção identitária.
\end{abstract}

Palavras-chave: Educação bilíngue, Literatura Surda, identidade.

\begin{abstract}
From many differences in the bilingual education and literary context, over the past few years researches on Deaf Literature has been emphasizing. This is result of the identification and selfaffirmation of the deaf people who searches the dissemination of their visual experimentation forms in diffusion of Deaf Literature. This article address bilingual education through practices of this literature contributing to the process of appreciating culture and deaf identity through the literary representations produced by this subject. The researches of Karnopp (2008; 2010), Quadros and SuttonSpence (2006) and Strobel (2009) are therefore important in the theoretical basis of this article, because they represent what is the most advanced in the theoretical field of the sensory experiences of the deaf person. Thus, the research developed seeks to contribute to the enrichment of deaf students' knowledge about their people, their culture and identity construction.
\end{abstract}

Keywords: Bilingual education, Deaf Literature, identity.

Recebido em 31-01-2018

Aceito em 14-06-2018

\footnotetext{
1 Mestre em Educação (UNIOESTE); Pós-graduação em Neupsicopedagogia e Educação Especial (Dinâmica Pós-Graduação); Graduada em Pedagogia (UNIOESTE); Graduação em Letras/Libras (Faculdade Eficaz). Docente na Universidade Tecnológica Federal do Paraná, campus Toledo.

${ }^{2}$ Especialização em LIBRAS (Facinter). Especialista em Educação (Faculdade Dom Bosco). Licenciada em Pedagogia pela UFSM. Graduação em Letras/Libras (Faculdade Eficaz); Agente Universitário (UNIOESTE/Toledo). Membro do Programa Institucional Relativo às Pessoas com Necessidades Especiais (PEE/Toledo).
} 


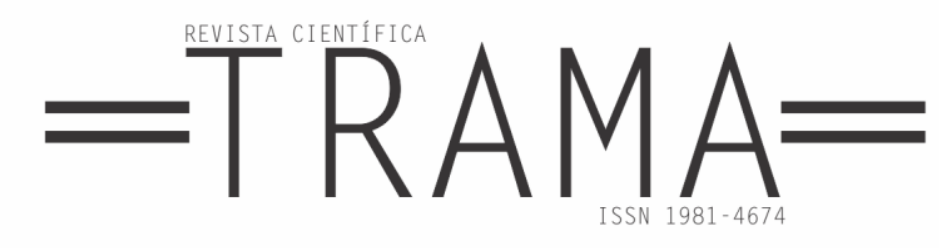

\section{$\mathbf{I}_{\text {NTRODUÇão }}$}

A contextualização histórica da pessoa com deficiência ao longo dos tempos registra-se por meio da dimensão de lutas e conquistas em uma época que para pertencer à sociedade exigia-se a "perfeição".

Refletindo-se sobre esta temática em relação às pessoas surdas não era diferente, pois, o fato de não poderem se comunicar oralmente representava uma incapacidade, seja para interação social, produção de tarefas ou religiosamente porque a pessoa surda era vista como pecadora, uma vez que não poderia confessar seus pecados.

Imprescindível citar também a visão terapêutica da medicina, em que a surdez era vista como "anormalidade", pois se necessitava de uma cura por meio de treinos para a produção da fala o sujeito poderia ser integrado à comunidade ouvinte. Segundo Quadros e Sutton-Spence (2006),

\begin{abstract}
Por muito tempo, as pessoas surdas foram cercadas pela noção fortemente defendida pelo oralismo de que as línguas faladas, tais como o inglês ou o português, eram as línguas a serem usadas para situações de status elevado e que "a sinalização surda" era inferior e se adequava somente para a conversação social (QUADROS E SUTTON-SPENCE, 2006, p. 115).
\end{abstract}

No que tange às conquistas de direito da pessoa surda a oficialização da Língua Brasileira de Sinais (Libras/2002) foi um marco, pois, garante o respeito ao seu meio de comunicação e sua socialização no trabalho, estudo ou lazer. A concepção clínico-terapêutica que atribui a surdez como uma deficiência e/ou patologia, pôde ser superada pela concepção socioantropológica que percebe a pessoa surda além da deficiência. Isso faz com que

\footnotetext{
${ }^{3}$ Destaca-se o uso de letra maiúscula nos termos "Surdo", "Identidade Surda", "Cultura Surda" e "Literatura Surda" por se tratar de atribuições específicas a um determinado povo, ou seja, povo surdo.

${ }^{4}$ Termo atribuído por Perlin e Miranda (2003).

${ }^{5} \mathrm{Na}$ pesquisa realizada, optamos pela utilização do termo povo surdo ao invés de comunidade
}

a torne capaz de assumir o seu espaço social, por meio do uso de sua língua, ou seja, uma questão de diferença em relação a sua condição linguística, que garante autonomia e sentido de pertencimento social.

Assim, o objetivo do presente artigo é refletir sobre a educação bilíngue mediante as produções da Literatura $\operatorname{Surda}^{3}$ como forma de ascendência da Cultura e Identidade Surda, destacando os aspectos que contribuem para a formação do "ser surdo" ${ }^{4}$ de ser e perceber o mundo. Logo, essas produções literárias, enriquecidas de caráter visual são distintas das divulgadas pela comunidade ouvinte que tem na modalidade oral-auditiva sua principal forma de comunicação.

Tendo como principal base teórica as pesquisas realizadas por Strobel (2009), Karnopp (2008; 2010) e Quadros e SuttonSpence (2006), o trabalho prevê delinear as produções literárias que contribuem para a valorização de aspectos de pertencimento do povo surdo, em um processo que os tornam referência para a construção identitária da pessoa surda, bem como para o enriquecimento da transmissão cultural que percorrem gerações.

Pretende-se com o escrito subsidiar práticas educacionais que visem à formação integral do educando de modo a valorizar seus conhecimentos prévios, sua língua natural e suas vivências cotidianas, logo,

[...] faz-se necessária a formação em serviço. E, preventivamente, cumpre examinar a formação inicial de todos os professores, de modo a assumirem a perspectiva da educação para todos ao longo de toda a vida, conjugando-se qualidade em equidade (CARVALHO, 2010, p. 173).

Assim, em seu aspecto inicial o artigo apresenta um plano geral da situação do povo surdo ${ }^{5}$ na conjuntura da legislação,

surda (constituída por pessoas surdas e ouvintes) por entender que a Literatura Surda resulta de experiências visuais partilhadas pelos sujeitos surdos, assim "[...] o povo surdo são sujeitos surdos que compartilham os costumes, história, tradições em comuns e pertencentes às mesmas peculiaridades culturais [...]" (STROBEL, 2009, p. 37). 


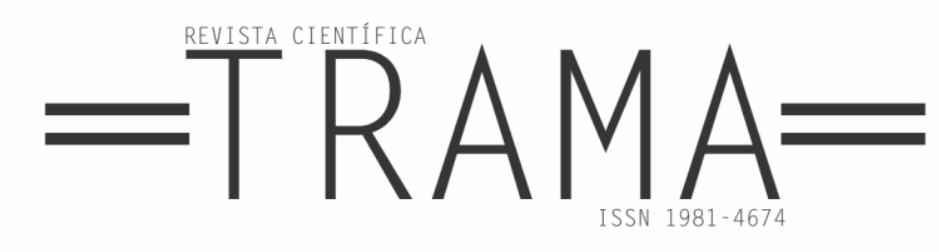

lutas, conquistas, associações, cultura e identidade própria.

No segundo momento, a organização textual evidencia especificamente o artefato cultural sobre a Literatura Surda e qual sua influência para a valorização da Identidade Surda. Ainda, especificam-se as diferenças de adaptações textuais e produções inéditas, como também em sua forma de apresentação, sendo impressa (com o acréscilitermo ou não da escrita de sinais) ou em forma de mídias destacando os aspectos fonológicos linguístico da Língua Brasileira de Sinais (Libras).

Por fim, destacam-se a importância da educação bilíngue mediante práticas de obras literárias da Cultura Surda que assumem uma contribuição estética e social de valoração de histórias de vida, seja em seu contato coletivo ou individual, que se materializam no contexto histórico a partir do momento que são registradas, produzidas e/ou reproduzidas.

\section{A literatura surda no CONTEXTO DE LUTAS E CONQUISTAS DO POVO SURDO}

Segundo o dicionário Aurélio em um conceito geral, literatura é o "Conjunto das obras literárias de um país ou de uma época", assim as produções registradas por inúmeros autores brasileiros compõem o acervo literário de obras que podem contribuir para o registro da história de um povo. Seja em suas contribuições para o progresso educacional, ou em sua modalidade de gêneros dramáticos, romances, poesias, contos infanto-juvenil, entre outros. Os registros de livros se tornam de suma importância para o processo de disseminação de regras sociais, identificação do ser ao assumir seu espaço ou até menos como materialização de contextos históricos tidos como referência para outras gerações.

Para Todorov (2009, p. 77), a literatura descreve e auxilia na compreensão da experiência humana sendo um "[...] pensamento e conhecimento do mundo psíquico e social em que vivemos", pois, o resultado da formação de nosso ser é produto das interações e influências que recebemos

do outro ao longo das gerações. Segundo o autor,

[...] a literatura abre ao infinito essa possibilidade de interação com os outros e, por isso, enriquece-nos infinitamente. Ela nos proporciona sensações insubstituíveis que fazem o mundo real se tornar mais pleno de sentido e mais belo. Longe de ser um simples entretenimento, uma distração reservada às pessoas educadas, ela permite que cada um responda melhor à sua vocação de ser humano (TODOROV, 2009, p. 23-24).

Assim, a literatura tornou-se condição essencial nos registros de produções enriquecendo as vivências e contribuindo para a transmissão cultural ao longo do contexto histórico, logo com o povo surdo não é diferente porque a Literatura Surda assume caráter peculiar de detalhes visuais que corroboram para a valorização de seus costumes, experiências e representações sociais. Tal contexto vai ao encontro das considerações do autor supracitado, pois, a necessidade do povo surdo em descrever suas experiências retrata inúmeros aspectos que contribuem para registro e transmissão de sua cultura contextualizando-a historicamente.

No entanto, somente com as políticas educacionais abordaram-se a defesa pelos direitos a Educação Especial, destacando a oficialização da Língua Brasileira de Sinais (Libras), pela Lei Federal $n^{\circ} 10.436 / 2002$, que em seu artigo $1^{\circ}$, parágrafo único conceitua esta língua como:

[...] a forma de comunicação e expressão, em que o sistema lingüístico de natureza visual-motora, com estrutura gramatical própria, constituem um sistema lingüístico de transmissão de idéias e fatos, oriundos de comunidades de pessoas surdas do Brasil (BRASIL, 2002, on-line).

Tais políticas proporcionaram reconhecimento da Língua de Sinais e a garantia de acessibilidade (todavia, a legalidade, não garante a sua efetivação), com isso, o povo surdo começou a ampliar o seu espaço social utilizando sua própria 


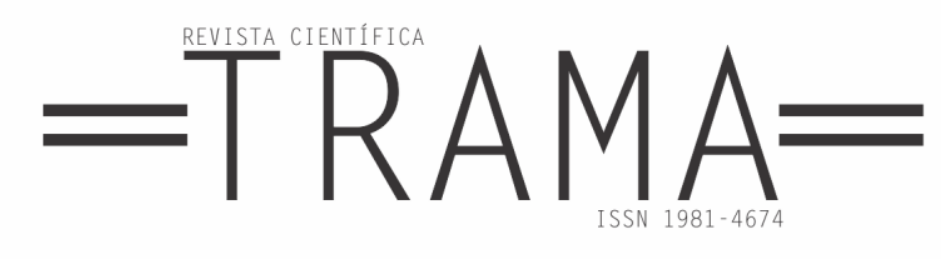

língua na modalidade visual-espacial. Pôde pelo uso de Libras registrar suas histórias de vidas, criar personagens fictícios, transmitir por gerações aspectos próprios de sua cultura, como: poemas, piadas, contos, fábulas que têm objetivo principal descrever situações vivenciadas entre seus pares.

No processo histórico de educação e socialização das pessoas surdas, de respeito à sua condição linguística e de garantia de acessibilidade comunicacional, percebe-se que a legitimidade da língua foi um marco imprescindível deste contexto, pois, segundo Karnopp (2008):

A partir da estreita relação que o contexto histórico pode estabelecer com o movimento literário, gostaríamos de ressaltar que, ao percorrermos alguns fragmentos da história do movimento surdo, percebemos também essa ligação. Em outras palavras, enquanto a Libras não era reconhecida ou enquanto era proibida de ser usada nas escolas, também não existiam publicações ou o reconhecimento de uma cultura surda ou de uma literatura surda. $\mathrm{O}$ ensino priorizava o aprendizado da fala e da língua portuguesa. Nas escolas, não havia espaço nem aceitação para as produções literárias em sinais. No entanto, acreditamos que entre os surdos circulavam histórias sinalizadas, piadas, poemas, histórias de vida, mas em espaços que ficavam longe do controle daqueles que desprestigiavam a língua de sinais. Especificamente no panorama brasileiro, é possível constatar ainda que para muitas pessoas torna-se irrelevante e, para outras, decisivamente incômoda, a referência a uma cultura surda (KARNOPP, 2008, p. 02).

No panorama social, a educação bilíngue está além do uso de duas línguas em um mesmo espaço (neste caso, a escola). Torna-se necessário uma proposta pedagógica embasada no multiculturalismo, em um espaço de valorização pessoal e reconhecimento do outro de sua forma integral, portanto, "A educação bilíngue para os surdos impõe aos educadores um novo olhar não apenas sobre a situação linguística em questão, mas, sobretudo, em relação às concepções axiológicas envolvidas nessa prática" (FERNANDES, 2003, p. 34).

Neste contexto, a Literatura Surda tornou-se um recurso importantíssimo na práxis educativa, consequentemente, no âmbito educacional porque as pessoas surdas iniciaram estudos sobre clássicos realizando adaptações literárias, traduções em Libras, bem como registros e produções inéditas ocuparam seu espaço ao lado do acervo bibliográfico já existente.

Por isso, os estudos que envolvem este contexto e conceitos, bem como as produções literárias, evidenciaram-se, pois, diante de uma cultura (marcada pela diferença linguística) distinta da cultura ouvinte, a pessoa surda assume uma identidade diferente que reflete em sua forma de perceber e conhecer o mundo e vice-versa. As autoras Caldas (2012), Quadros e Sutton-Spence (2006) e Perlin (2010) descreveram em suas pesquisas a individualização na "Identidade Surda" caracterizada pela forma própria do jeito surdo de ser e experimentar suas vivências, por consequência,

\begin{abstract}
A identidade surda é uma alteridade que se constrói por meio de um sistema linguístico. Por isso, é necessário que os surdos estejam em constante contato com a língua de sinais, isso é uma necessidade ontológica que condicionará a formação de um sujeito ativo e cidadão. E essa identidade vem se autenticando cada vez mais, principalmente pela defesa da Libras, a língua natural dos surdos (CALDAS, 2012, p. 143).
\end{abstract}

Sendo uma das características evidentes nestas produções literárias a luta constante contra a dominação da cultura ouvinte, em um ambiente que só poderia pertencer à sociedade quem era oralizado (surdos treinados vocalmente para produzir a fala), pois, segundo LADD (2003), “[...] utilizando a língua de sinais criativamente e como uma forma de arte é um ato de empoderamento em si mesmo para um grupo linguístico minoritário oprimido" (apud QUADROS; SUTTON-SPENCE, 2006, p. 115). 


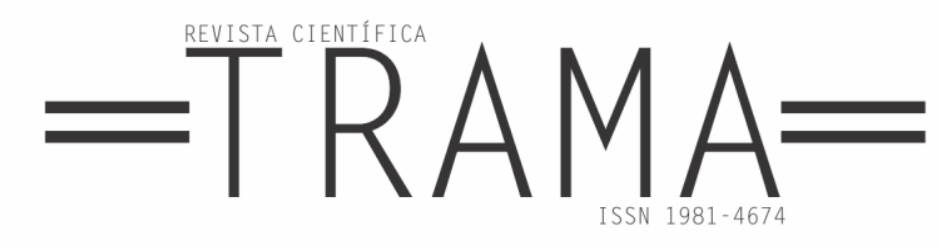

O empoderamento pode ser materializado mediante as construções sociais da Pessoa Surda garantindo adaptações visuais no espaço que ocupa e permitindo que suas atuações ocorram de forma autônoma. Um exemplo de produções dos surdos que garantem o empoderamento são os artefatos culturais.

A autora Strobel (2009) conceitua artefatos culturais não apenas como "[...] materialismo cultural, mas àquilo que na cultura constitui produções do sujeito que tem seu próprio modo de ser, ver, entender e transformar o mundo" (STROBEL, 2009, p. 40). Nesse sentido, apresenta alguns dos mais importantes artefatos para construção da Cultura Surda, sendo: experiências visuais, linguístico, familiar, literatura surda, vida social e esportiva, artes visuais, política e materiais.

No que tange o artefato cultural referente à Literatura Surda pode-se destacar que são influências perpassadas por várias gerações do povo surdo enfatizando o modo de ser e perceber o mundo próprio da pessoa surda, pois, "[...] refere-se às várias experiências pessoais do povo surdo que, muitas vezes, expõem as dificuldades e/ou vitórias das opressões ouvintes" (STROBEL, 2009, p. 62).

Narrada em Libras, a Literatura Surda assume significado, a partir do momento que difunde a sua língua e as características do povo e comunidade surda, visto que a,

Literatura surda é a produção de textos literários em sinais, que traduz a experiência visual, que entende a surdez como presença de algo e não a falta, que possibilita outras representações de surdos e que considera as pessoas surdas como um grupo linguístico e cultural diferente (KARNOPP, 2006, p. 102).

Assim, as produções dos próprios sujeitos surdos massificaram-se em uma geração de surdos politizados que lutam pelo direito de "ser surdo" com cobranças ao uso de sua língua, presença de profissional tradutor/intérprete, legendas, adaptações visuais, janelas com intérpretes e outras tecnologias assistivas que garantem sua autonomia e a qualidade de vida.
Em contrapartida, tal posicionamento social dos surdos exigiu um profissional "remodelado" na área de educação, ou seja, um professor bilíngue capaz de respeitar a autonomia diante do uso da língua de sinais, bem como a valorização da diversidade cultural e múltiplas identidades.

Exigiu-se dos professores uma mudança de conduta, sendo o mediador deste contexto, um profissional com percepção de que "[...] o trabalho educacional precisa ser orientado para os pontos fortes da criança, para seus talentos, para o respeito as suas diferenças" (FERNANDES, 2011, p. 48).

Neste processo de "remodelamento", as práticas focadas em valorização das experiências dos alunos surdos têm na literatura surda possíveis referências de "ser surdo" a partir do momento que expõem vivências de fortalecimento social e valorização de sua língua.

\section{Produções literárias da COMUNIDADE SURDA}

Evidencia-se que as diferentes produções literárias do povo surdo (que buscam traduzir as experiências visuais, culturais e linguísticas próprias das pessoas surdas) podem ser divulgadas por meio de produções de mídias ou impressas.

As produções midiáticas possuem um aspecto peculiar de valoração das expressões não manuais, ou seja, transmitem sua mensagem por meio das expressões faciais e corporais, aspectos indissociáveis da língua de sinais. Que por muitas vezes estão presentes somente neste contexto literário porque ao serem transcritos ou traduzidos para a língua portuguesa não transladam a emoção impecavelmente representada em sua forma visual.

Os registros de diferentes gêneros textuais por meio de mídias, como: poesias, piadas, histórias infantis e até adaptações musicais (que são traduzidas para língua de sinais) buscam representações linguísticas significativas aos surdos e não uma tradução realizada de forma literal, da Língua Portuguesa para a Libras o que não é representativo aos surdos. 


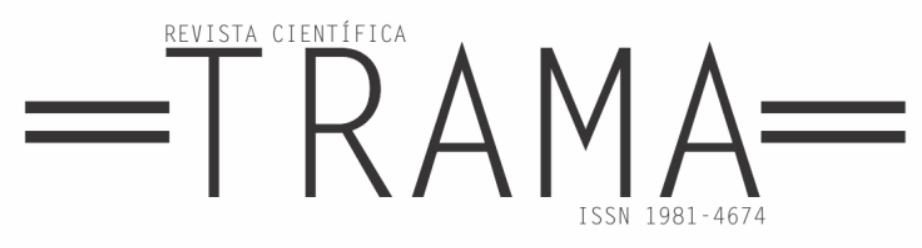

(2006):

Segundo Quadros e Sutton-Spence

A experiência sensorial de pessoas surdas é uma característica central de muitos poemas na língua de sinais. $O$ som - e a ausência dele - tem lugar muito pequeno nessas poesias e é raro encontrar um poema na língua de sinais que foque em qualquer sentido a perda da audição para pessoas surdas (QUADROS E SUTTON-SPENCE, 2006, p. 117).

Um exemplo midiático seria a poesia intitulada "Os cinco sentidos" do autor Nelson Pimenta, em que ao representar os sentidos humanos, $\mathrm{o}$ autor trabalha $\mathrm{o}$ aspecto mais importante: a percepção do mundo por meio da visão. Nessa poesia, a "falta de audição" não é o panorama central, pois, o autor retrata de forma magnífica a utilização da visão frente à audição no processo de percepção de mundo.

Segundo Rosa (2006, p. 63), a utilização de mídias "[...] tem muito para ajudar, já que mostra as imagens que as pessoas surdas fazem em língua de sinais, apresentando a cultura, a identidade, as expressões faciais e corporais", tais aspectos são perceptíveis nas traduções de histórias e fábulas em Libras.

No que se refere às produções impressas destacam-se as adaptações dos clássicos da literatura infantil que podem ser reorganizados de acordo com as vivências visuais do povo surdo. Entre tais produções encontramos: Rapunzel Surda, Cinderela Surda e o Patinho Surdo que buscam fazer referência às vivências e experiências dos surdos, assim como, a diferença linguística, a valorização da Cultura e Identidade Surda. Karnopp (2010, p. 170) corrobora que tais adaptações têm como objetivo "[...] registrar histórias dos clássicos da literatura, com uma aproximação com as histórias de vida e as identidades surdas".

Da mesma forma que se tornam referência para a criança surda, ao ler uma história infantil, alimenta seu contato com o lúdico de se tornar príncipe ou princesa em consonância com a utilização de Libras e com as experiências sociais que vivência. Aborda-se, como exemplo, a adaptação
Cinderela para "Cinderela Surda" que segundo Alves e Karnopp (2009, p. 73),

[...] a luva branca foi substituída pelo sapatinho de cristal, pois, na versão da Cinderela Surda (no prelo), as mãos que sinalizavam estavam em foco (ALVES; KARNOPP, 2009, p. 73).

Figura 1 - Capa dos livros adaptados dos clássicos da literatura infantil
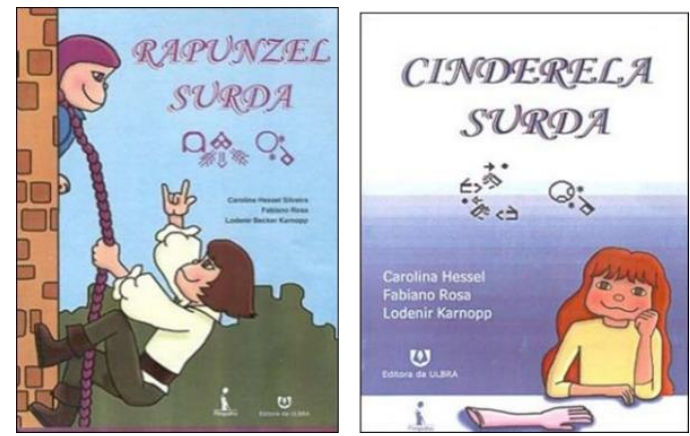

Fonte: Site Escrita de Sinais (2010).

O processo de recriar histórias já conhecidas e adaptá-las ao contexto de experiências visuais constrói um campo infinito de possibilidades, de se reconhecer mediante o uso de sua cultura e de perpassála por gerações, uma vez que, para Alves e Karnopp (2009, p. 72), os "Surdos recontam histórias para outros surdos e reconstroem por meio da língua e da cultura, os sentidos veiculados pelo texto que serviu como ponto de partida para a criação de um outro texto".

As produções inéditas literárias de pessoas surdas (como: Casal Feliz, História da Árvore, Ivo, Os cinco sentidos etc.) são carregadas de aspectos visuais, o que facilita trabalhar temas diferenciados com surdos mais jovens. Pois, na história "Casal Feliz" do autor Cleber Couto (on-line), podemos trabalhar a diferença linguística entre surdos e ouvintes, assim como, a possiblidade da interação social e relacionamentos afetivos.

Já, no livro "Ivo" produzido pela Federação Nacional de Educação e Integração dos Surdos Feneis/RS compondo o "kit Libras é Legal" apresenta conceitos relacionados à cidadania trabalhando além do aspecto familiar, questões relacionadas à educação e trabalho. 


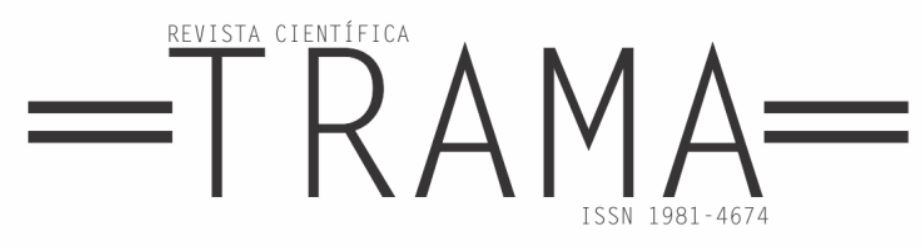

Figura 2 - Capa do livro Ivo kit libras é legal

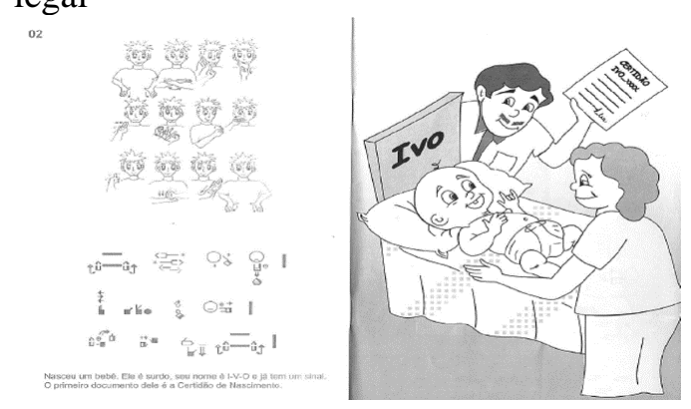

Fonte: adaptação das pesquisadoras

No entanto, ao serem apresentados, mesmo com tradução, tais livros podem ser incompreendidos pela comunidade ouvinte por estarem "presos" as percepções auditivas da comunicação. Por isso, ao interpretar uma poesia ou uma piada surda é preciso, para o ouvinte, desvencilhar das percepções auditivas que carregam ao longo da vida e transcender as percepções visuais tão bem representadas pelo povo surdo.

De acordo com Porto e Peixoto (2011, p.167): "Para refletir sobre literatura visual é preciso que pensemos que esta modalidade de texto surgiu no momento em que as pessoas surdas se apropriaram do saber sobre o poder de produção imagética de sua língua".

Algumas representações impressas podem estar acrescidas da escrita de sinais, o que contribui como um registro e disseminação de um aspecto enriquecedor do uso da língua. A pesquisadora Gesser (2009) situa a escrita da língua de sinais em um contexto histórico que:

[...] a ideia de representar as línguas de sinais remete-nos à história de uma coreógrafa américa, chamada Valerie Sutton. Em 1974, Valerie chamou a atenção da comunidade científica dinamarquesa das línguas de sinais com a criação de um sistema para registrar as danças de seus alunos. A transcrição dos "sinais da dança" para a "escrita de sinais" inicia-se a partir do contato de pesquisadores da universidade de Copenhagem com a colaboração de Valerie com base em seus registros gravados (GESSER, 2009, p. 42).
No Brasil, as pesquisas sobre a escrita de língua de sinais se iniciaram a partir de 1996, com a participação da pesquisadora Marianne Stumpf (2009). Após realizar estudos e pesquisas sobre o processo de aprendizagem de crianças surdas expostas à utilização da escrita de sinais, concluiu que ocorre uma evolução neste processo do desenvolvimento, ampliando o conhecimento e o vocabulário dessas crianças, além de estimulá-las a buscar mais saberes e aplicá-los.

Percebe-se que, independente do registro, seja em sua forma de disseminação escrita ou midiática, as produções literárias das pessoas surdas são indispensáveis para identificação cultural e identitária, o que preconiza uma comunicação estruturada na modalidade visual-espacial.

Uma das formas de disseminação para a ascensão e valorização desta cultura encontra-se no cotidiano escolar da educação bilíngue, porque por meio da utilização de diferentes produções literárias a criança surda terá uma possibilidade de gêneros textuais, identificando-se ou contrapondo-se. A utilização da Literatura Surda como recurso em sala de aula contribui para o processo de letramento e para o dialogismo de forma reflexiva, permitindo ao educando surdo comunicar suas ideias em sua língua natural.

\section{EudcaÇão bilíngue mediante O USO DA LITERATURA SURDA}

A luta pela valorização da diversidade e respeito à igualdade de direitos perpassa o contexto de sala de aula, pois, esta caminhada se inicia desde a teorização do Projeto Político-Pedagógico (PPP) até a sua materialização no cotidiano escolar mediante as práticas docentes. Portanto, o professor deve estar preparado para enfrentar situações que envolvam o multiculturalismo e as identidades diversas que serão trazidas pelos alunos. Estas práticas refletem momentos enriquecedores de troca de experiências, sendo que o professor assume papel de extrema importância na mediação de um diálogo reflexivo. 


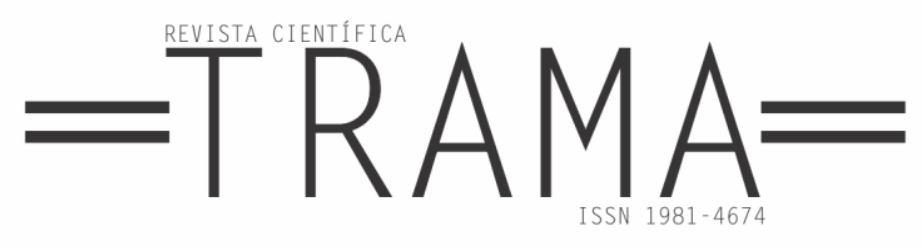

\section{Segundo Fernandes (2011),}

A sala de aula deve ser um espaço que reconheça as relações no mundo, as relações de cultura, os valores das diferentes culturas, criando sempre oportunidades de se buscarem as múltiplas possibilidades de se solucionar um problema. É preciso, portanto, que se desenvolva propostas pedagógicas abertas aos diversos caminhos que se podem seguir ao tentar encontrar a solução de um problema (FERNANDES, 2011, p. 48).

Além da valorização de registro cultural, a literatura contribui para os aspectos de mudanças de percepções de sujeitos influenciando ativamente em seus conceitos sociais, pois ao atuar na transformação individual reflete na amplitude do coletivo. Por isso, conforme afirma Todorov (2009, p. 76), "[...] a literatura pode muito. Ela pode nos estender a mão quando estamos profundamente deprimidos, nos tornar ainda mais próximos dos outros seres humanos que nos cercam, nos fazer compreender melhor o mundo e nos ajudar a viver".

No campo da educação bilíngue, a Literatura Surda permite evidenciar aspectos importantes da percepção visual deste sujeito e contribui para minimizar barreiras atitudinais constantemente evidenciadas pelo uso de uma comunicação espaço-visual em um contexto em que a língua majoritária é uma língua oral. Logo é "[...] neste sentido que as mudanças e o reconhecimento legal da língua de sinais não são suficientes. A Cultura Surda, a experiência visual e o uso da língua de sinais sustentam o encontro e a vida da comunidade surda" (KARNOPP, 2010, p. 164).

É evidente o destaque da Literatura Surda no processo de formação da identidade porque permite as crianças surdas a identificação de aspectos linguísticos do uso de sua língua, além de colaborar com a ludicidade e criatividade, sendo relacionada de forma direta com o processo histórico de difusão da Cultura Surda ao longo das

6 Conforme Perlin (2010, p. 59) o “[...] ouvintismo deriva de uma proximidade particular que se dá entre ouvintes e surdos, no gerações, pois, as histórias dos clássicos infantis:

[...] contada na língua de sinais de determinada comunidade linguística, é constituída pelas histórias produzidas em língua de sinais pelas pessoas surdas, pelas histórias de vida que são frequentemente relatadas, pelos contos, lendas, fábulas, piadas, poemas sinalizados, anedotas, jogos de linguagem e muito mais. O material, em geral, reconta a experiência das pessoas surdas, no que diz respeito, direta ou indiretamente, à relação entre as pessoas surdas e ouvintes, que são narradas como relações conflituosas, benevolentes, de aceitação ou de opressão do surdo (KARNOPP, 2010, p. 171).

Este processo constante de autoafirmação vivenciado pelo povo surdo também é descrito por Strobel $(2009$, p. 63) ao relatar ser este um processo permanente de mudança histórica que "[...] garante o valor dos direitos culturais para o povo surdo, transformando as relações de poder, desde a vida cotidiana até os espaços mais públicos".

$\mathrm{O}$ fortalecimento do contato entre seus pares e a identificação mediante sua cultura serão um processo decisivo para $o$ rompimento com a influência ouvintista ${ }^{6}$ de subordinação. Assim, com a transição das experiências e as percepções acerca do mundo por meio do visual, favorece-se a construção de uma real Identidade Surda.

$\mathrm{O}$ processo da educação bilíngue permeia todo o contexto escolar, e vai além do ensino de duas línguas de maneira que é "[...] comprometida em promover a legitimidade e a autoridade, até então negadas, a grupos minoritários exige posicionamento ético e político. Isso significa pensar para além das fronteiras estabelecidas pelas línguas envolvidas no processo". (FERNANDES, 2003, p. 40).

Neste campo, o professor é um dos agentes importantes em fortalecer a interface teoria/prática mediante atuação pedagógica

qual o ouvinte sempre está em posição de superioridade". 


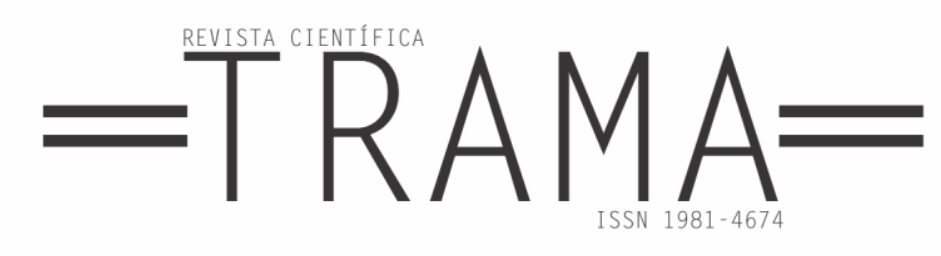

por meio do trabalho com as produções literárias surdas garantindo à criança surda $\mathrm{a}$ percepção de sua diferença cultural e linguística, compartilhando em seu processo educacional o modo que percebe o mundo, ou seja, por experiências visuais. Assim, não ocorrerá mesmo que, de forma indireta, a imposição de uma única cultura (a ouvinte) para estes estudantes.

\section{Considerações finais}

As produções literárias são imprescindíveis para a continuação da cultura de qualquer povo ao redor do mundo. Isso ocorre também no processo de pertencimento do povo surdo e até mesmo de uma comunidade surda, que muitas vezes é uma parcela minoritária no território em que ocupa, pois “[...] os povos surdos estão cada vez mais motivados pela valorização de suas "diferenças" e assim respiram com mais orgulho e riqueza suas condições culturais!" (STROBEL, 2009, p. 96).

Todas as formas de divulgação das produções literárias, escritas e midiáticas são importantes para a disseminação da língua de sinais e seus aspectos linguísticos, demonstrando que não ocorre superioridade ou inferioridade de uma língua oral para a língua de sinais, mas que ambas possuem estruturas próprias que capacitam para a interlocução de qualquer mensagem. Assim como, a importância de reafirmar suas tradições e recuperar histórias que foram reprimidas.

Em vista dos estudos realizados, pode-se perceber que a Literatura Surda assume um espaço de contribuição para a ascendência na valorização da Identidade e Cultura Surda. O trabalho desenvolvido na educação bilíngue, mediante a utilização das diferentes produções literárias do povo surdo, constitui uma oportunidade de enriquecimento do conhecimento dos alunos surdos sobre seu povo, sua cultura e o a constituição identitária, além de representar o engajamento destes sujeitos em lutas, empoderamento, contra o ouvintismo e repressões culturais.

\section{$\mathbf{R}_{\text {EFERÊNCIAS }}$}

ALVES, Antônio Carlos C.; KARNOPP, Lodenir Becker. O Surdo como contador de histórias. In: LODI, Ana Claudia B. Letramento e Minorias. Porto Alegre: Mediação, 2009.

BRASIL. Lei $\mathrm{n}^{\circ} 10436$ de 24 de abril de 2002. Brasília: Presidência da República, Casa Civil, Subchefia para Assuntos Jurídicos. Disponível em: < http://www.planalto.gov.br/ccivil_03/leis/2 002/L10436.htm >. Acesso em: 23 de mai. 2018.

BRASIL. Decreto $\mathrm{n}^{\circ} \mathbf{5 6 2 6}$ de 22 de dezembro de 2005. Brasília: Presidência da República, Casa Civil, Subchefia para Assuntos Jurídicos. Disponível em: <http://www.planalto.gov.br/ccivil_03/_ato 2004-2006/2005/decreto/d5626.htm>.

Acesso em: 23 maio 2018.

CALDAS, Ana Luiza Paganelli. Movimento Surdo: identidade, língua, cultura. In: PERLIN, Gladis; STUMPF, Marianne. Um olhar sobre nós surdos: leituras contemporâneas. 1. Ed. Curitiba: CRV, 2012.

CARVALHO, Rosita Edler. Removendo barreiras para a aprendizagem. Porto Alegre: Mediação, 2010.

ESCRITA DE SINAIS. Cinderela Surda e Rapunzel Surda. 2010. Disponível em: <https://escritadesinais.wordpress.com/201 0/08/30/cinderela\%C2\%A0surda-erapunzel-surda/> . Acesso em: 23 maio 2018.

FERNANDES, Eulalia. Surdez e Bilinguismo. Porto Alegre: Mediação, 2011.

FERNANDES, Sueli de Fátima. Educação bilíngue para surdos: identidades, diferenças, contradições e mistérios. Tese de Doutorado Curitiba: UFPR, 2003.

GESSER, Audrei. LIBRAS? Que língua é essa?: crenças e preconceitos em torno da 


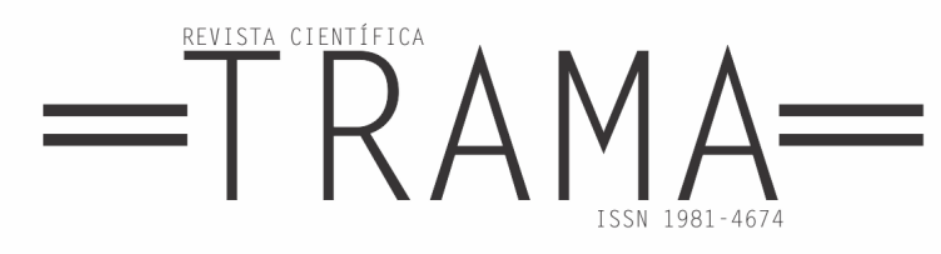

língua de sinais e da realidade surda. São Paulo: Parábola Editorial, 2009.

HOLANDA, Aurélio Buarque de. Dicionário Aurélio Online. Disponível em: $<$ https://dicionariodoaurelio.com/>. Acesso em: 23 maio 2018.

KARNOPP, Lodenir Becker. Produções culturais de surdos: análise da literatura surda. In: Cadernos de Educação. Pelotas/RS: UFPEL, 2010. p. 155-174.

KARNOPP, Lodenir Becker. Literatura Surda. Universidade Federal de Santa Catarina, 2008. Disponível em: <http://www.libras.ufsc.br/colecaoLetrasLi bras/eixoFormacaoEspecifica/literaturaVisu al/assets/369/Literatura_Surda_TextoBase.pdf>. Acesso em: 23 maio 2018.

KARNOPP, Lodenir Becker. Literatura Surda. In: ETD - Educação Temática Digital, Campinas, v. 7, n. 2, p. 98-109, jun. $2006 . \quad$ Disponível em: <http://www.ssoar.info/ssoar/bitstream/han dle/document/10162/ssoar-etd-2006-2-

karnopp-literatura_surda.pdf?sequence $=1>$. Acesso em: 23 maio 2018.

PERLIN, Gladis T. T. Identidades Surdas. In: SKLIAR, Carlos (Org.). A Surdez: um olhar sobre as diferenças. Porto Alegre: Mediação, 2010.

PERLIN, Gladis T. T.; MIRANDA, Wilson. Surdos: o Narrar e a Política. Estudos Surdos, P. Vista, UFSC, Florianópolis, SC, Brasil, 2003. Disponível em: <https://periodicos.ufsc.br/index.php/ponto devista/article/view/1282/4249>. Acesso em: 23 maio 2018.

PORTO, Shirley; PEIXOTO, Janaína. Literatura Visual. Revista Letras Libras. Biblioteca UFBP Digit@1.p. 165-196. 2011. Disponível em <biblioteca.virtual.ufpb.br/files/literatura_v isual_1462975268.pdf $>$. Acesso em: 23 maio 2018.

QUADROS, Ronice Müller de.; SPENCESUTTON, Rachel. Poesia em língua de sinais: traços da identidade surda. In: QUADROS, Ronice Müller de. Estudos Surdos I. Petrópolis RJ: Arara Azul, 2006.

ROSA, Fabiano Souto. Literatura Surda: criação e produção de imagens e textos. In: ETD - Educação temática digital 7. 2006., 2, p. 58-64. Disponível em: <https://periodicos.sbu.unicamp.br/ojs/inde x.php/etd/article/view/791/806>. Acesso em: 23 maio 2018.

STROBEL, Karin. As imagens do outro sobre a cultura surda. Florianópolis: Ed. UFSC, 2009.

STUMPF, Mariana. Escrita de Sinais II. Universidade Federal de Santa Catarina UFSC. Florianópolis, 2009. Disponível em: <http://www.libras.ufsc.br/colecaoLetrasLi bras/eixoFormacaoEspecifica/escritaDeSina isII/assets/492/TEXTO-

BASE_EscritaSinais2.pdf>. Acesso em: 23 de mai. 2018.

TODOROV, Tzvetan. A literatura em perigo. Trad. MEIRA, Caio. Rio de Janeiro: DIFEL, 2009. 